\title{
AC 2009-85: USING COMMUNITY ADVISORY PANELS (CAPS) FOR THE DEVELOPMENT OF A STEM PROFESSIONAL DEVELOPMENT MODEL FOR TEACHERS OF AMERICAN INDIAN STUDENTS
}

\section{Kurt Becker, Utah State University}

Kurt Becker is the Department Head of the Engineering and Technology Education Department at Utah State University. He is currently the Co-Principal Investigator for the National Science Foundation (NSF) funded National Center for Engineering and Technology Education and Principal Investigator for the NSF funded project: Communities of Effective Practice: A professional STEM Development Partnership Model for Teachers of American Indian Students. His areas of research include adult learning cognition, engineering education professional development and technical training. He works with the technology teacher education program in the department and teaches undergraduate and graduate courses. He has extensive international experience working on technical training and engineering projects funded by the Asian Development Bank, World Bank, and U.S. Department of Labor, USAID. Countries where he has worked include Armenia, Bangladesh, Bulgaria, China, Macedonia, Poland, Romania, and Thailand. He is currently a consultant on a USAID-funded project that involves workforce development and enterprise competitiveness.

\section{Jim Barta, Utah State University}

Jim Barta, Associate Department Head of Regional Campus and Distance Education at Utah State University has been involved in multicultural mathematical educational research, teaching and curricular development for over 15 years, with a particular emphasis in Native American mathematics education. He currently has two projects; he works to enhance math education with indigenous teachers in the rural highlands of Guatemala and he collaborates with upper elementary and middle school teachers on The Northern Ute Reservation to improve their STEM teaching.

\section{Rebecca Monhardt, Utah State University}

Rebecca Monhardt is an Associate Professor at Utah State University. Her educational background includes a Ph.D. in Science Education from the University of Iowa, an M.Ed in Curriculum and Instruction from Texas A\& M University and a B.S in Elementary Education from the University of Houston. She is a former elementary science teacher. Over the past twelve years in Utah, Dr. Monhardt has worked with Navajo teachers and students and her research interests deal broadly with the topic of relevance in elementary science education. She is particularly interested in place a context for making science meaningful for all students, especially those who have been traditionally underrepresented in science. 


\title{
Using Community Advisory Panels to Develop a STEM Professional Development Model for Teachers of American Indian Students
}

\begin{abstract}
The Communities of Effective Practice: A Professional STEM Development Model for Teachers of American Indian Students project is NSF funded with a vision to improve American Indian student achievement in science and mathematics. This project implements a professional development STEM model for teachers in American Indian schools by linking Utah State University (USU) engineers and teacher educators with teachers in grades 4-6. The model is designed to include standard-based and researchbased mathematics and science curricula using engineering and technology concepts and strong links with tribal elders, parents, and community leaders. The core partners for this effort include the Navajo Nation in the Mexican Hat Elementary School in Mexican Hat, Utah and the Northern Ute Nation in the Todd Elementary School, in Fort Duchesne, Utah.
\end{abstract}

The three-year proof of concept grant: 1) designed a series of culturally relevant professional development modules for teachers of grades 4 through 6 that include an American Indian perspective and that satisfy national and state of Utah core curriculum requirements in math and science; and 2) developed a template that describes the organization and methods for creating a Community Advisory Panel (CAP) of teachers, American Indian students, community leaders, parents, and tribal elders who work to incorporate important cultural knowledge reflecting their specific community into math and science curricula.

The findings presented are based on surveys, phone interviews and observations conducted with teachers and CAP members representing each elementary school. The findings indicate that it is critical to have fully functioning CAPs, as their input and support is tantamount to the success of the professional development, and in turn, has effects class-wide and school-wide. 


\section{Introduction}

The American Indian population of the United States was estimated at 1.86 million in 2000 , with a total of about 4 million reported multiracial ethnicity [1]. It is one of the fastest growing ethnic groups, with about 533,000 children attending public schools. The achievement of American Indian students on standardized tests nationwide shows that our educational system does not meet their needs as learners. The latest results in grades 4 and 8 on the National Assessment of Reading and Mathematics show lower average scores of American Indian students compared to all other students in the nation in both subject areas [2]. The numbers of American Indian students performing at or above basic, and at or above proficient levels, were also lower than those of all other students in mathematics and reading. These results are consistent with graduation rate data for American Indian students. In 2004, half of the American Indian elementary students who took the end-of-level criterion referenced test did not demonstrate proficiency in math. Montana, a state with American Indian students accounting for $11.3 \%$ of the total K-12 school population, reports that $72 \%$ of the middle school students and $24 \%$ of the high school students who dropped out were American Indian [3]. At the same time, the state reports less than one percent of all students in the state taking Advanced Placement tests are American Indian. A summary of research on American Indian students reveals a similar picture nationwide [4].

This alarming disproportion calls for revision of the educational approaches used with American Indian students. On April 30, 2004, the President of the United States signed an Executive Order on American Indian and Alaska Native Education that states "It is the purpose of this order to assist American Indian and Alaska Native students in meeting the challenging student academic standards of the No Child Left Behind Act of 2001 (Public Law 107-110) in a manner that is consistent with tribal traditions, languages, and cultures." [5] Research shows that the disjunction between traditions of home and school could have a consequence of conflicting situations for the students and, thus, affect their attitudes toward formal education and their relevant academic achievement [6]. The resulting non-satisfactory student progress of American Indian students and the subsequent negative lifelong outcomes bring to the forefront the urgent need for incorporating home and culture in their educational experiences.

The role of teachers of American Indian students in providing effective educational opportunities aligned with the above Executive Order and the ongoing efforts for increased achievement of students nationwide is unquestionable. However, teachers often lack the knowledge and experience for planning and delivering instruction that considers the cultural specifics of tribal life and how they relate to education. Mathematics and science, two of the most important content areas targeted by the ongoing educational reform, are, at the same time, areas of lowest achievement of American Indian students. A culturally relevant professional development model aimed at teachers of American Indian students can provide educators the knowledge and skills needed to teach in a culturally responsive way. This study explores a culturally responsive professional development model for elementary teachers of American Indian students utilizing engineering concepts as vehicles for math and science content teaching and learning in 
elementary grades. The use of engineering approaches in math and science instruction allows for a culturally responsive alignment with the nature of American Indian educational approaches and traditions.

\section{Math and science culturally relevant professional development}

Effective professional development is considered key for ongoing school reform and improvement [7] [8] [9]. The accountability required from teachers and schools and the focus on increased student achievement pose significant challenges for educators across content areas and grade levels nationwide. However, while a model of culturally responsive professional development should ultimately lead to better student achievement, it should be centered on culturally specific characteristics and learning approaches of American Indian learners. This would be possible by building and using in everyday educational practices the knowledge about American Indian culture, traditions, values, and beliefs and their influence on the individual as a person and as a learner. A model of professional development for teachers of American Indian students accounts for the influence of American Indian cultural values and beliefs on the learning outcomes.

Professional development in math and science has its established traditions. Models of effective professional development have been developed and analyzed with respect to teachers' goals and students' needs [9]. Research shows that professional development that addresses the immediate concerns of teachers and students in formats aligned with teacher learning and specific classroom implementation are most effective for students and appealing to educators [8] [9]. A culturally responsive professional development model for teachers of American Indian students should build on these models but should include specific elements observed in the Native educational tradition and be engaging for teachers and students alike. Culturally relevant professional development in STEM would provide teachers with the opportunity to gain the knowledge and experience needed to teach effectively in a culturally responsive way.

\section{Overview of American Indian educational traditions}

Traditional education of the American Indian people is known to have been informal, situated in nature and provided by experts in particular areas regardless of their age. This approach to education is in unison with the core values of harmony and relatedness of indigenous people [10]. Content and load of educational opportunities are selected considering individual abilities and do not force the learner to proceed if mastery has not been achieved. The heart of American Indian educational tradition is "not primarily the acquisition of specific skills or factual knowledge. Rather it is learning how to be a human being. That is, how to live a life of utmost spiritual quality" [10].

The American Indian educational approach has traditionally been community-based, with educational experiences immersed in everyday lives. Parents, relatives, and elders take the role of teachers most of the time; often all other community members, including children, become teachers and receive respect and appreciation for sharing their knowledge. Rituals and ceremonies have central roles in this process of knowledge 
acquisition. Games and game-like situations attended by children and adults alike would also present opportunities for learning. Klug and Whitfield [11], describe indigenous education in terms of current day educational terminology as "experiential learning followed by authentic assessment" (p. 29). The related process consists, generally, of observation, followed by practice and demonstration.

With over 550 officially recognized tribes in the United States, the diversity within the people that identify themselves as American Indian is significant. While some beliefs and traditions are common for most tribes, there are specific traditions, values, and beliefs recognized only within a certain tribe. There is a lack of written documents that describe these traditions, and the details about them are known and passed from generation to generation by tribal elders. Together with the community-based nature of education, this method of communicating specific cultural information calls for involvement of community members in the process of learning about tribal traditions and knowledge and their relevance to classrooms and instruction. The professional development model described here takes in account the need for obtaining authentic cultural elements to be incorporated in instruction by including Community Advisory panels (CAPs) as a driving force of the culturally relevant model.

\section{The Project}

Communities of Effective Practice (CEP) is a National Science Foundation funded project to develop a STEM professional development model for teachers in American Indian schools which links Utah State University (USU) engineers and teacher educators with teachers in grades 4-6. The model is designed to include standard-based and research-based mathematics and science curricula using engineering and technology concepts and strong links with tribal elders, parents and community leaders. The ultimate impact of the professional development model is the improvement of teaching and learning of Science, Technology, Engineering, and Mathematics (STEM).

Currently, the project is in year three of the three-year proof of concept grant. It is working to: 1) design a series of culturally relevant professional development modules for teachers of grades 4 through 6 that include an American Indian perspective and that satisfy national and state of Utah core curriculum requirements in math and science; and 2) develop a template that describes the organization and methods for creating a Community Advisory Panel (CAP) of teachers, American Indian students, community leaders, parents, and tribal elders who work to incorporate important cultural knowledge reflecting their specific community into math and science curricula.

Project evaluation is designed to: 1) identify changes, if any, in participating teachers' knowledge of science and math principles, shifts in their attitudes toward teaching science and math and changes in their science and math teaching techniques to reflect a more culturally relevant content; 2) assess the impact on students, as reported by teachers; 3) describe the process of the formation, function and effectiveness of the CAPs; and 4) assess the robustness of the program model to gauge readiness for wider dissemination. 
The professional development models and Community Advisory Panels (CAPs) were developed in two American Indian communities: the Mexican Hat Elementary School community (located in the San Juan School District, and serving a student population that is $99 \%$ Navajo) and the W. Russell Todd Elementary School community (located in the Uintah school district, and serving a student population that is predominantly Ute). These two locations were selected because they serve different cultural communities and therefore offer insights to support the scale-up of the project for additional cultural communities.

\section{Community Advisory Panels (CAPs)}

A unique core element of the CEP project is the organization and active participation of the Community Advisory Panels (CAPs). They involve parents, community leaders, elders, or other members of the Native American community, in collaboration with administrators and teachers. Their goal is to explore the wealth of knowledge of the specific Native American community and to connect it to STEM curriculum development and implementation through professional development. Community Advisory Panels were organized in both sites.

The CAP of the Navajo site consists of the elementary school principal, a USU professor in elementary science education, a parent, the district staff developer, the curriculum director for the district, and two Navajo elders. One of the elders is involved with the media center that develops Navajo materials for the school district, and the other is responsible for the Navajo language curriculum in the district. The staff developer on the CAP is also Navajo. She is a former teacher and was appointed as Chair of the CAP. The parent on the team is also Navajo and currently has children at the school where the project takes place. The school principal, the curriculum director, and the university professor are not Navajo.

The CAP meets once a month for 2 to 3 hours. It is described as a collegial group that runs the project of implementing Navajo traditions into the curriculum from the bottom up. The CAP creates all curriculum materials, and the university CAP member reports that her role in the project is to coordinate and bring the research strand into the curriculum development and the classroom activities. The group reports show regular attendance with all members attending all meetings. The chair of the CAP is credited with the successful organization and attendance. The meetings have a formal agenda in place, and minutes are taken and reported.

The Uintah Basin CAP originally formed in the Ute school included the principal of the elementary school and the principal of the adjacent middle school where students attend $6^{\text {th }}$ grade, a USU professor in elementary mathematics, the Ute educational director, and two Ute community members. One of the community members was chosen as a chair of the CAP. The Ute CAP members were selected because of their knowledge of Ute traditions, language, and culture. Several new community members have been asked to 
join, consult, and contribute to the professional development. The CAP members are directly involved in the curriculum development and implementation. Three theme-based teams were organized - one from each grade. One of the Ute elders is currently working specifically with each grade-team of teachers as they co-construct the culturally responsive lessons.

\section{CAPs Research Question and Methods}

One of the purposes of the project is to investigate the process of organizing, establishing, and functioning of the Community Advisory Panels at both sites. One of the research questions for the study is: What are the characteristics of a well-functioning and established Community Advisory Panel as part of a culturally relevant professional development model? The investigation helps to establish a general framework of CAP formation while at the same time incorporating specific characteristics evolving from the different cultural elements at each site. The data collection for the study is guided by the following questions:

1. What are the key characteristics of the CAP members as professionals, individuals, and community members that affect their successful participation and contribution to the CAP mission?

2. What are the rules that guide a successfully functioning CAP? What are some of the challenges encountered in the process, and how does the CAP address them?

3. What are some culturally specific elements that differentiate the CAPs at the two sites? How are they relevant to a larger model of CAP?

The study uses a collective case study design [12]. The data for the study was gathered using multiple instruments: observations, interviews, and a number of CAP documents, informal conversations, and field journals. The concepts that emerged from the data were grouped into related categories and from these categories, common threads emerged. The emerging themes centered on the change that was intended: the development of a cohesive community advisory panel in which all voices were heard and that a sharing of power was present which would ultimately result in meaningful change. In addition, the rationale for the CAP formation is supported by survey results. Through the data analysis, the goal is to scaffold a CAP model as an integral part of a culturally relevant professional development model while at the same time reflect on the important details that emerge in the presence of cultural specifics.

Characteristics of the CAPs formation emerged from surveys conducted with parents and teachers from the participating schools. For example, an issue that surfaced from the parental surveys was the relationship between school and community. The parents were asked if they believed a positive relationship existed between the school and the community. Two thirds of the parents at the Ute site felt that such relationship existed, with the other one third of the surveyed parents being neutral. These results provided rationale for building on and strengthening the relationship between school and community and including community members as CAP participants. In addition, the parents were able to write in a challenge they perceived as influential to the schools' 
ability to serve the students well. Two thirds of the parents stated "lack of parental support" as a significant challenge. This data suggested that parental participation in CAPs might be beneficial for both the community and the school.

The teachers involved in the project also completed a pre-project survey. They indicated that while they have confidence in their math and science content knowledge, they lacked knowledge of the culture of their students. In this aspect, the role of the relationship between school and community surfaced again and reinforced the need for collaboration between all parties interested in the academic success of the students.

The cultural perspectives of the project also contribute to challenges not immediately visible. For example, when we first contacted community members at the Northern Ute site, some of our efforts to collect specific cultural information were not successful. We learned, however, that according to Ute traditions, stories are told by elders in the fall. When we inquired about the information at the culturally appropriate time, we were successful. This shows that it is imperative that the CAP members have access to culturally relevant information from sources closely involved with the specific tribal traditions and not make assumptions about availability of needed resources that might jeopardize deadlines and timelines.

The approach to each CAP configuration, its role in the project and responsibilities, should be clearly defined in the beginning of any similar professional development model. Community member involvement is imperative. The CAP must not exclude them under the assumption that the literature would provide sufficient and appropriate information on American Indian traditions and their relevance to education. In addition, it is important to give the community members a voice in the CAP decisions rather than only include them as sources of information.

It is also appropriate to provide some training for teachers and administrators regarding cultural proficiency and competencies as part of their participation in a CAP. Becoming aware of our own beliefs and assumptions about other people and cultures is an appropriate step toward assuring effective collaboration with people of different worldviews about education. It may also be appropriate to ask CAP members to share their beliefs about the area of contribution to the professional development process. This would allow CAP participants to become acquainted with each other and to focus more effectively on the professional development. It would also contribute to the collegial atmosphere of collaboration.

Although specifically developed within the CEP project, the Community Advisory Panels may be used with similar professional development models applied in communities with different cultural traditions and beliefs. Our experience shows that the panel should have balanced representation of the cultural and educational strands of the project. Some of the key CAP positions should include a knowledgeable and respected community leader, a community member involved in education, and possibly a current or retired teacher representing the culture or a parent closely engaged in education. These CAP members establish and maintain the vital connection with the larger community and drive the 
process of establishing the cultural relevance of the curriculum. The CAP should also include a school administrator and curriculum specialist or a teacher. These members are invaluable for establishing the connection between the core curriculum, the requirements of standardized assessment, the curriculum materials created by the CAP and its classroom applications. A college or university faculty knowledgeable of culturally relevant instruction and it's applications in the classroom brings to the CAP the strengths of research-based teaching and bridges the content and the cultural strands for creating and delivering an effective professional development experience.

CAP organization and management are other important considerations. Our experience shows that CAP members should have clearly assigned roles and tasks, with a trusted leader to guide the CAP work. The member assignments depend on the goals and objectives of the CAP, but the leader should be a person who unites the CAP and feels comfortable communicating with all of them about their responsibilities. In addition, the CAP needs to stay focused on the desired culturally specific outcomes of the collaborative work and needs to communicate them to the teachers during the professional development. The CAP members need to work on establishing working relationship with the teachers engaged in the project. Thus, they could assist with the culturally appropriate implementation of the curriculum, which would additionally strengthen the connections between planning, delivery, and implementation of the culturally responsive curriculum.

Selection of the CAP members should be carefully done and should consider personal and professional factors. The most important characteristics are:

1. Members' ability to contribute to the project and its progress through knowledge and training.

2. The skills they bring to the CAP considered important for the project's success based on project's goals and objectives.

3. Their own motivation to contribute and collaborate.

These factors will be different for each CAP member, but, for this project, are critical. For example, administrators concerned with school change and increased student achievement bring to the CAP the experience of school leadership. In addition, administrators negotiate the ongoing initiative and its contributions to the progress of the school with the other administrative units, including the district and state. One of the main challenges for the school mentioned by parents in their survey was "lack of district support". In contrast, parents participating in the CAP are concerned with their children's current and long term academic success while, at the same time, they are in a position of personally reflecting on possible asynchrony between school and home. Their immediate motivation would help focus on existing discrepancies and possible steps for change.

These examples show that CAPs need to involve a variety of professionals and individuals who can critically reflect on different perspectives of the educational process and its connection to professional development, cultural relevance of instruction, and 
student achievement. However, another issue that surfaced from data analysis is the number of people involved in CAPs. While multiple perspectives and voices are important, it is also important that all of these voices be heard and considered. Thus, the optimal number of CAP members is five or six. The personal and professional engagements of the CAP members can be a challenge when it comes to CAP meeting participation. It was observed that this size of a CAP is possible to manage organizationally, while it allows for involving key representatives of all groups. If the need for additional input arises, the CAP members may decide to invite other contributors.

Among the features that support effective group work and collaboration, several issues arose with respect to the formation and functioning of a CAP. First, while everyone's participation and opinion should be heard and valued, it is imperative that the group has a CAP chair. The role of a Chair, as determined from our experience, is critical for coordination and communication between all members. For example, one of our CAPs has a very pro active chair that is a community member, familiar with a multitude of aspects of the educational system, as well as with the (lack of) cultural relevance in it. This CAP reports regular meetings with strong participation of all members. In contrast, the other CAP went through some challenging times. Although all CAP members chose the Chair unanimously, there was some lack of coordination of actions and communication between members of the CAP, which impeded the curriculum development process. Thus, leadership is imperative for the structure and the purpose of a CAP.

Second, the CAP needs to have clearly defined tasks and deadlines to refer to and complete. All CAP members are dedicated to the project but still have other personal and professional responsibilities. A schedule with assignments and responsibilities with relevant completion deadlines allows for accountability and balance of the load among members. The process of finding relevant cultural materials to include in the classroom, the relevant teacher development, and the actual classroom implementation is long and includes numerous elements. By providing individual assignments directed toward the achievement of the main goal, the process is manageable and focused.

The formation and functioning of a Community Advisory Panel within a culturally responsive professional development model is a process with challenges and successes. Although there is a common ground in building the general structure of a CAP, there are details, many of them culturally specific, that should be considered key for its optimal functioning and progress. The experience gained from the two sites where CAPs are already formed and functioning provides important guidelines for creating a CAP and continuously monitoring its development. This process will continue and will bring new highlights to the model of this important component of the Communities of Effective Practice project and the possibilities for its growth beyond Utah's borders. 


\section{Professional Development}

The other critical focus of the project was the design of a series of culturally relevant professional development modules for teachers of grades 4 through 6 that include an American Indian perspective and that satisfy national and state of Utah core curriculum requirements in math and science.

Investigators from Utah State University planned professional development sessions around (a) a formalized professional development model and (b) a set of clearly defined outcomes to guide the process. Having these two components in place prior to planning and delivering professional development enhances the quality of the work. The outcomes of the professional development workshops serve a valuable purpose in guiding the project regarding these critically important elements. At the time of this paper, professional development and lesson development was in process. The following describes the professional development and lesson development process. The findings at each site, Mexican Hat Elementary and Todd Elementary are described separately.

During the year long professional development at Todd Elementary, approximately 100 hours were conducted. The emphasis of the experiences was on improving teachers' elementary math content and pedagogy, mathematical problem solving and alignment of curriculum and instruction with the NCTM Standards using engineering and technology concepts, Ute culture and culturally responsive instructional techniques, and enhancing the teachers' knowledge and experience in mathematical instructional leadership. Each team met face to face to create a total of three lessons. After lesson development, instruction took place, was taped and evaluated. All CAP members were collaborators in this process. They helped the teachers incorporate Ute culture and language (contextually and mathematically) when appropriate in each lesson. They advised the teachers in culturally responsive methods of teaching.

The professional development engaged the teachers as members of a professional learning community (community of professional learners development) where participants are not only learners but also are obligated to assume team responsibilities which include designing and presenting collaboratively created math lessons (content coaching) and collectively analyzing and evaluating videotape of their classroom instruction (lesson study).

The focus was on the development of instructional thematic math lessons using a modified lesson study approach. One or more CAP members assigned to each teaching team provided cultural guidance. The themes are:

Grade 4 - (Weather - Cycles)

Grade 5 - (Earth's Surface - Changes)

Grade 6 - (Solar System - Scale/Relative Position)

In the development of lessons using the lesson study approach, teachers collaborated in their groups to create a math lesson specific to their grade level and theme. Following the development of each math lesson, one of the members of each team implemented the 
lesson in their classroom and videotaped their instruction. The teacher teaching the lesson completed a self-reflection summarizing 1) what took place, 2) what worked, 3) what did not, and 4) what could be done to enhance the lesson. The team members not teaching watched the video of the completed lesson and completed their own summary as previously outlined. Teachers on each team met and prepared a collaborative and mutually agreed upon plan for lesson enhancement. All summaries were written and submitted no later than one week after the lesson was taught.

At the next professional development session, the groups reviewed the video as a team and analyzed the evaluation. Specific weaknesses/strengths in the lessons were noted and this data was used when constructing the next lessons. The cycle of creating plans, teaching and evaluating them occurred at each professional development session. Additionally, Elders prepared presentations on Ute culture, language, and pedagogy and shared with the teachers. The team co-constructed a wiki-space with all members having access. This space was the repository of plans, teaching videos, cultural information, Ute language dictionary, etc. It is a virtual manual that teachers outside of the project can access and hopefully use in their efforts to provide culturally responsive teaching in their communities. Teachers and project organizers also held virtually mini-meetings interspersed between physical meetings. The project organizers used computer audio and visual technologies to answer questions, provide encouragement, and update teachers on the progress of the project. A final professional development session reviewed all products developed and lessons.

Since this is a "Proof of Concept" project, both professional development sites varied in their approach. Mexican Hat Elementary used a different professional development approach which included teacher participants being trained in the use of the Reformed Teaching Observation Protcol (RTOP) created by the Evaluation Facilitation Group of the Arizona Collaborative for Excellence in the Preparation of Teachers (ACEPT). Participating teachers, along with the USU professor, used this instrument to observe teacher lessons. The lessons aligned to the Utah Science Core Curriculum for grades 4-6. While the focus of the instruction was on STEM concepts, opportunities for Navajo elementary students to practice literacy skills were imbedded throughout all lessons and strategies. Appropriate aspects of Navajo culture have been built into the lessons by CAP members.

\section{Project Findings Related to Professional Development}

The findings are based on phone interviews conducted with teachers and CAP members representing each elementary school.

Phone interviews were conducted with six teachers who participated in the professional development workshop series. Three of the teachers were associated with the Mexican Hat Elementary, and the other three teachers were associated with Uintah Basin's Todd Elementary. The teacher interviews sought to capture their impressions of 1) the current challenges that they face in the classroom and the current efforts to address these 
challenges (school and classroom needs assessment) and 2) the strengths and weaknesses of the professional development experience.

Teachers identified the need for increased parent involvement, increased staff collaboration, and efforts to support current transitions within the school. The majority of the teachers acknowledged parental involvement as a need or challenge, and some teachers expressed the view that parents do not care how well their students' perform in school, and therefore, do not support the education process within the home. A couple of teachers noted the need for school staff members (principal, other teachers, etc.) to collaborate more with one another to accomplish their school's goals.

Because the main purpose of the professional development workshops is to provide teachers with culturally relevant material to incorporate into their teaching strategies, it is important to have an understanding of how teachers feel about teaching culturally relevant information within their classrooms. Whether or not teachers believe it is important to provide culturally relevant information may influence whether they attend the professional development workshops or if they will adapt their current plans to include information they receive from the workshops.

When asked how important it is to provide culturally responsive math and science activities to students on a scale of one to ten, four out of the six teachers reported a score of nine or higher. Those who provided a score of less than nine reported that culture is important to acknowledge, but a teacher's primary goal is to provide instruction that supports student achievement on statewide assessments.

Overall, teacher feedback for the professional development workshops at Todd Elementary was very positive. When teachers were asked about the weaknesses of the professional development workshops very few teachers acknowledged any, although they did make suggestions for improving the program. Teachers who reported positive feedback on the professional development program were impressed with the hands-on approach to improving student achievement in science. In addition, teachers from Todd Elementary enjoyed collaborating with other teachers and educators to develop new ideas to improve student achievement.

"Getting together as a team with the other 4th \& 5th grade teachers, talking about how to teach, bounce ideas off of each other, expand our thinking. I think the collaboration made us all better teachers." - Todd Elementary Teacher

This feedback regarding collaboration was not present in the comments from teachers at Mexican Hat Elementary, because unlike the professional development program at Todd Elementary, the program at Mexican Hat Elementary used a coaching model for professional development and therefore did not include opportunities for collaboration. However, teacher interviews resulted in positive feedback resulting from participation in project professional development. 
"For me, it [the CEP program] has given me all kinds of different ideas to assist the discovery by children. The more they get their hands on it and the more they can get into it, the more attention they pay to it." - Mexican Hat Elementary Teacher

Further probing on teachers' impressions of the program revealed concerns regarding how the goals and structure of the professional development program were communicated to them, and the overall logistics of scheduling the professional development workshops. Some of the teachers were confused as to the purpose of the professional development workshops based on either a lack of communication or miscommunication with their supervisors on the nature of the project. Other teachers found the workshops to be personally useful, but they were unsure how to communicate to fellow teachers the benefit of incorporating culturally relevant material into science and math curricula.

"We didn't really understand what was being asked of us until very late in the spring. Even the more experienced teachers didn't understand what was going on." - Todd Elementary Teacher

"For me, personally, there are absolutely no weaknesses. However, helping teachers see and understand that this work will be effective for teaching science has been tough. There are teachers resisting this approach still." - Mexican Hat Elementary Teacher

In addition to the concerns about communication, some teachers discussed logistical challenges that the program faced. One respondent at Todd Elementary recommended scheduling the professional development sessions at times that least interfered with teaching.

Teacher interviews provide insight into the program's impact with regard to changes in classroom-level outcomes and school-level outcomes. Teachers were asked what, if any, differences they have noticed in their own teaching strategies as well as their students' engagement level in class and test performance. In addition, teachers were asked to reflect on any changes that emerged at the school-level, such as changes in other teachers' instructional strategies and/or other students' engagement level and test performance.

Classroom-Level Outcomes. The majority of the teachers interviewed from both Todd Elementary and Mexican Hat Elementary reported that they 1) were more aware of the cultural aspect to their instruction, 2) had more resources to make cultural changes to their lesson plans, and 3) made changes to their instructional strategies after participating in the professional development series. Their comments reflect improvements in both the cultural relevancy of their instructional practices and the depth of the scientific content in their instruction.

"This is the one area where I have a freedom to teach the way I want to teach. I am having as much fun as the kids are, because I don't have to do direct instruction. ... It was a big thing when there was recent press coverage of a North Dakota dinosaur 
mummy found (on tribal lands?) back in 1999, my kids were so proud to already know about it, from our connections to actual paleontologists, long before the media announcements." - Mexican Hat Elementary Teacher

"I follow a plan better, we have clearer goals, and we assess our accomplishment of the objectives immediately. I think the teachers have better science knowledge too." Mexican Hat Elementary Teacher

"I used their [professional development workshops] template to increase the comprehension of my student's reading. This has really helped me, to use the same format for reading that I use in science. ... By template I mean their directive reading strategy: Identify the content, purpose, vocabulary, and give the students some background with pre-reading." - Todd Elementary Teacher

"By the end of the year the students were very comfortable telling me about their culture, because I did put in place a pattern of asking questions one-on-one, then talking about the cultural knowledge openly after they checked in with their parents." - Todd Elementary Teacher

School-level Outcomes. Four out of the six teachers reported sharing the information they received from the project with fellow teachers; however, only two teachers, both at Mexican Hat Elementary, reported evidence of school-wide changes following the project. These two teachers noted a sense of greater emphasis on science, math, and the importance of cultural materials at Mexican Hat Elementary.

"I seem to be modeling a cheerful success story for the other teachers...this is what is working in my classroom pep talks. I have noticed other science teachers being more hands-on and bringing in more cultural materials, so I think it is fair to call that an overall result." - Mexican Hat Elementary Teacher.

\section{Conclusions}

It is critical to have fully functioning CAPs, as their input and support is tantamount to the success of the professional development, and in turn, has effects class-wide and school-wide. If properly developed and utilized, a professional development model for teachers in American Indian schools in grades 4-6 can be realized using standard-based and research-based mathematics and science curricula using engineering and technology concepts. It is important to have strong links with tribal elders, parents and community leaders to improve of teaching and learning of Science, Technology, Engineering, and Mathematics (STEM). 


\section{References}

[1] Census 2000 (2006). Census 2000 Demographic Profile Highlights. Retrieved on October 2, 2006, fromhttp://factfinder.census.gov/servlet/SAFFIteratedFacts?_event=\&geo_id=01000US\&_geoCon text $=01000 U S \& \_s t r e e t=\& \_c o u n t y=\& \_c i t y T o w n=\& \_s t a t e=\& \_z i p=\& \_l a n g=e n \& \_s s e=0 n \& A c t i v e G$ eoDiv=\&_useEV=\&pctxt=fph\&pgsl=010\&_submenuId=factsheet_2\&ds_name=DEC_2000_SAF F\&_ci_nbr=010\&qr_name=DEC_2000_SAFF_R1010\&reg=DEC_2000_SAFF_R1010\%3A010\& _keyword=\&_industry=,and R1010\%3A007\&_keyword=\&_industry=

[2] NIES (2005). National Indian Educational Study Part One: The performance of American Indian and Alaska Native fourth- and eight grade students on NAEP

[3] Office of Public Instruction (2005). American Indian Education Data Sheet. Helena, MN. Retrieved on September 30, 2006, from http://www.opi.mt.gov/pdf/indianed/IEFADataFactSheet.pdf\#search=\%22data\%20american\%20i ndian $\% 20$ students $\% 20$ graduation $\% 20$ number $\% 20$ dropout $\% 22$

[4] Demmert, W. G., Grissmer, D, \& Towner, D. (2006). A Review and Analysis of the Research on Native American Students. Journal of American Indian Education, 45(3),. 5-23

[5] White House Press Release (2004). Executive Order: American Indian and Alaska Native Education. Retrieved on September 29, 2006, from

http://www.whitehouse.gov/news/releases/2004/04/20040430-10.html

[6] Ladson-Billings, G. (1995). Toward a theory of culturally relevant pedagogy. American Educational Research Journal, 32(3), 465-490.

[7] Glickman, C. D., Gordon, S. P., \& Ross-Gordon, J.M. (2007). SuperVision and instructional leadership: a developmental approach (7th ed.). Boston, MA: Pearson

[8] Gordon, S. P. (2004). Professional development for school improvement: empowering learning communities. Boston, MA: Pearson Education.

[9] Loucks-Horsley, S., Love, N., Stiles, K. E., Mundry, S., \& Hewson, P. (2003). Designing professional development for teachers of science and mathematics (2nd ed.) Thousand Oaks, CA: Corwin Press

[10] Reagan, T. (1996). Non-Western educational traditions: Alternative approaches to educational thought and practice. Mahwah, NJ: Lawrence Erlbaum Associates.

[11] Klug, B. J., \& Whitfield, P. T. (2004). Widening the circle: culturally relevant pedagogy for American Indian children. NY: RoutledgeFalmer.

[12] Creswell, J. W. (2008). Research design: qualitative, quantitative, and mixed methods approaches. ( $2^{\text {nd }}$ ed.). Thousand Oaks, CA: Sage Publications 